\title{
O casal na cultura de hoje: implicações psicopatológicas
}

\author{
GEORGES ABRAHAM *
}

Um dos dilemas clentificos fundamentais que 0 homem «arrasta» consigo desde há séculos, é o da predominância na sua vida de elementos hereditários, inatos, ou então da primazia de factores adquiridos, da experiência existencial ela mesma.

Este dilema engloba também o casal. Em certos momentos, com efeito, o casal pode ser considerado como resultado de uma selecção cromossómica, de um destino inscrito no genes, noutros momentos, ao contrário, como resultado de pressões sociais ou de modelos culturais.

Ou existe um casal tendo como fundamento a tipologia, a complementaridade de temperamentos de dois associados, ou então temos o casal fundamentado, ao contrário, sobre as circunstências da história pessoal, sobre a complementaridade das necessidades psico-afectivas adquiridas. O que equivale à afirmação de que existe a possibilidade de imaginar um casal de estrutura cultural, e impregnado de cultura, ou a alternativa de um casal situado antes ou depois do cultural, um casal de ressonância essencialmente biológiea ou natural.

Em qualquer caso o homem foi descrito como «animal social» e a sua identidade indi-

* Pslcanalista. Professor no Departamento de Pslquiatria da Universidade de Geneve. Professor de Sexologia na Faculoade de Medicina da Universidace de Marselha. Texto de uma conferencla proferlda num eurso de aperfeiçoamento da Socledade suíça de Psiquitatila. vidual não parece frequentes vezes mais que - reflexo de uma identidade colectiva.

Onde começa exactamente o indivíduo em relação ao meio social que o circunda? Onde colocar exactamente os limites da individualidade? O indivíduo năo é concebível como entidade monolítica: é antes um conjunto de órgãos, de células, de moléculas. Um conjunto de reacções, de pontos de vista, de perspectivas diferentes. Ele tem dois hemisférios cerebrais que podem entrar em dissidência entre si. Tem no interior dele mesmo factores hereditários transmitidos pelos antepassados e influências derivadas dos contemporâneos. fi vitima de um papel social, de condicionamentos, de ideais, que the foram infligidos ou transmitidos.

Dispersando-se por memórias que the restam do seu passado, agarrando-se a um Eu dificilmente definido, habitado pela ilusão da independência e autonomia, embora procurando sempre o contrário, o individuo não pode ser senão um ponto de referência, umat entidade relativa, incapaz de vida própria sem o contributo dos seus semelhantes. $O$ isolamento absoluto do individuo conduziria na prática à morte, mesmo tendo em contia que este individuo isolado esconde dentro de si objectos interiorizados, como são designados pela psicanálise, que tornariam esta suposta solidão intensa, uma ilusão.

O casal portanto, todos os casais, podem ser concebidos antes como a construção voluntária e livre de uma relação, com o prolongamento tnevitável da incompletude individual. o casal sexual não é senão uma forma de vida comunitária, que existia já no seio da 
familia originária e que existe numa quantidade apreciável de outras relações humanas possiveis.

O casal, por sua vez, pode ser concebido como uma entidade supra-individual, mas tendo uma autonomia intrinseca em relação ao meio clrcundante ou, contrariamente, pode ser percebido por exemplo como uma «célula» da sociedade, uma parte de um grupo constituído ou como núcleo comunitário. Face ao casal como ponto de chegada, haveria o casal como ponto de partida, como meio de inserção mais evidente e mais funcional no conjunto da colectividade.

O casal tornar-se-ia assim um meio de coesão social mais do que um instrumento de isolamento e de separação em relação aos outros. A individualidade perderia então parte da sua força e exigência no casal, visto que ela se apagaria no seio de necessidades de mais vasta envergadura, numa solidariedade reciproca. Como se constitui afinal o casal? Há cordenadas especiais que entram, sem dúvida, em consideração, tais como a vizinhança física, o encontro num dado lugar, a associação frequente. Coordenadas temporals igualmente: proporção de idade, de educação; uma possibilidade de repetir os encontros.

No entanto, os ideais, os modelos, os estereótipos de uma cultura, de uma época especifica, desempenham um papel indiscutível na constituição e manutenção do casal. Ideais relacionados com a estrutura do casal, com - seu funcionamento; dizendo respeito aos critérios de beleza, de entendimento, de sex appeal. Modelos de conquista, de fidelidade, de comportamento social, de educação dos filhos.

Além disso a intervenção inevitável de todos as factores inconscientes implicando a projecção dos próprios desejos profundos, a reparação de situações infantis e pessoais, a introjecção selectiva de certos modelos, de preferência a outros.

Resulta de tudo isto, como se sabe, diferentes protótipos de casais «normais». Casals onde um dos dois associados está destinado a desempenhar um papel essencialmente protector, ou então um papel de tranquilização narcísica, para o outro. Casais onde pelo contrário predominam as necessidades de dependência de um dos associados, ou as necessidades de ser maternalizado ou assistido. Casais onde, por exemplo, a ligação de base está representada por uma necessidade de apoio e defesa reciproca em relação ao meio ambiente; casais onde a ligação fundamental está representada pela necessidade de se ajudar mutuamente a «crescer», na direcção de um aperfeiçoamento pessoal. Ligações de base, sejam voltadas para o exterior sejam para o interior do próprio casal.

Ligaçóes de base estruturadas principalmente em relação ao passado, à tradição, versus os casais onde ludo se estrutura $\mathrm{em}$ relação ao futuro, aos projectos, às intenções. Ligaçōes de base, enfim, constituídas em relação ao real, a idcias concretas ou sentidas como tais, ou inversamente constituídas em relação ao imaginário, ao abstracto, aos desejos.

Na nossa época e na nossa cultura, assistimos a três acontecimentos revolucionários envolvendo o casal, cujas consequências sobre este ainda estão longe de ter sido plenamente efectivadas.

Em primeiro lugar, o fim da família patriarcal, que foi imagem de um mundo de tipo agrícola e estável, substituída pela familia chamada nuclear, reflexo de um mundo industrializado e tecnológico: esta família sendo de estrutura mais mutável ou instável.

Em segundo lugar, a sociedade impôs a igualdade entre os sexos, associada à emancipação feminina: isto significou o fim do homem como chefe de familia.

Em terceiro lugar, uma contracepção eficaz modificou a organização familiar, especialmente no que diz respeito à procriação, com introdução paralela dos conceitos de paternidade e maternidade responsáveis.

No ponto de vista da dinâmica efectiva do casal resultou daí a ruptura da intimidade. Esta intimidade se já estava ameaçada na familia patriarcal, era simultaneamente apropriada por esta: a família alargada estabelecia limites protectores em relação ao meio exterior. Hoje o casal deve prestar contas do seu funcionamento ao grupo social ao qual pertence, deve renunciar à posse e ao isolamento, deve estar pronto a dividir com outros os problemas, as emoções, as insuficiências. A relação de submissão relativa de um dos «partenaires», em geral a mulher, foi substituída por um «discurso» que visa alcançar o consentimento mútuo. Este facto reduz a importância do apelo emocional. A aproximação infraverbal é admitida mas como forma de comunicação: não deve ser contaminada por nenhum perigo fusional. A troca reciproca dos papéis a desempenhar tornou-se uma atitude corrente no casal: papéis pater- 
nais ou maternais, activos ou passivos, de fraqueza ou de força. Tudo isto leva a vantagens para a dinâmica do casal, mas pode também produzir facilmente crises de identidade do casal, ele mesmo.

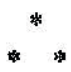

A noção de normalidade, que em si parece de tal modo evidente, na prática é frequentes vezes difícil de delimitar. Normalidade estatística ou normalidade ideal? Normalidade como conceito, como exigência, ou normalidade como ponto de referência operacional?

Assim, pode tornar-se aberrante tentar definir o casal normal, a cujo modelo todos os casais deveriam ser comparados.

Cada casal pode, assim, apresentar um certo número de problemas, de crises, de momentos de desequilíbrio, sem ser por isso considerado como afectado de uma patologia bem definida. Uma série de circunstâncias, entre as quais se contam os determinismos históricos e culturais, são portanto susceptíveis de condicionar até que ponto certos comportamentos devem ser considerados ou não como realmente doentios ou perturbados.

Por outro lado, resta considerar em que medida manifestações aparentemente patológicas no casal, năo são senão a repercussão de perturbações sociais. Uma dada sociedade pode tornar-se patogénea para os casais frágeis, ou não suficientemente estruturados. Ao propor um modelo de casal ideal, inexistente na realidade, o contexto social pode produzir uma patologia sob a forma de angústia, de culpabilidade, de necessidade de «performance» em todos os casais, que se consideram Inadequados face ao modclo proposto.

Uma patologia efectiva pode, no entanto, já estar presente no casal de um modo potencial. Um dos membros do casal, ou mais correntemente os dois membros, em proporções eventualmente diferentes, podem encarar a sua união de uma maneira neurótica. Dito de oiltra manelra, a procura do associado efectuou-se nesse caso em função de um sofrimento ou de uma necessidade doentia. Um dos «partenaires» projecta sobre o outro as múltipilas facetas do seu mundo interno, estando simultaneamente pronto para receber as projecções análogas e complementares do outro. Assim o "partenaire» pode tornar-se, para todos os efeitos, figura paternal ou maternal, ora boa ra má. Pode tornar-se a reprodução parcial de uma situação infantil ou a reencarnação de um irmão ou irmã. Pode passar a representar uma parte não aceite do próprio, por exemplo, uma parte correspondendo à passividade ou à actividade; ou aquela parte associada à bondade ou à maldade. Funções defensivas mais complexas podem igualmente ser projectadas e atribuídas ao outro: duas «fórmulas» relacionais neuróticas deste tipo são habitulalmente descritas.

Uma é a relação dita anaclítica, de dependência maciça: aqui o «partenaire» deve poder suportar uma espécio de transplantação vinda do outro, que tende a funcionar com a sua personalidade, como se fosse um parasita desta.

A outra forma de relação neurótica bem conhecida é a que idenominamos de contra-fóbica: aqui o associado é escolhido mercê das suas pretensas capacidades para proteger o outro, de um medo vivenciado como incontrolável.

Mas não são só os sindromas neuróticos reconhecidos que determinam este tipo de alianças. Ưma pessoa de tendências sádicas perversas pode procurar um partenaire potencialmente sentido como possuidor de disponibilldades masoquistas; um exlblcionista pode escollher um presumivel voyeurista. Uma personalidade de estrutura psicopática pode escolher alguem que possa desempenhar o papel de vítima; um imaturo afectivo pode ligar-se a um personagem sentido como autoritário e dominador.

Mesmo os psicóticos, os pré-psicóticos, ou os casos limítrofes, podem encarar um vínculo de casal em função do seu sofrimentio, da sua angústia, ou das suas necessidades defensivas.

Como caso extremo, uma ligação dentro de um casal pode ser equivalente a uma «passagem aro acto» de poderosas fantasias internas, de estruitura delirante ou subdelirante.

Nesses casos extremos, também, a constituição de um casal pode ser considerada como expressão de impulsos autodestruidores ou autopunitivos inconscientes: o partenaire tendo então por função o efectuar, pouco a pouco, a «demolição» do cônjuge. A procura neurótica ou psicopatológica do outro pode ser, sem dúvida, efectuada a pretexto de um grande amor, da descoberta do ser ideal, ou de uma atracção erótica irreststivel.

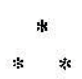

Partindo destes conceitos, é possivel dividir a psicopatologia mais corrente do casal 
em dois grupos relativamente individualizados.

Um primeiro grupo é constituído por perturbaçôes que podem ser denominadas «doenças no casal», enquanto que um segundo grupo pode ser classificado como «doenças du casal».

Por doença no casal entendem-se todas as perturbações «importadas», por assim dizer, para o casal por um dos associados ou pelos dois em conjunto. Pode tratar-se de conseuêencias relativas às exigências psicopatológicas que, como já vimos, já influenciaram ou determinaram a escolha do partenaire. Uma escolha neurótica de um companheiro pode conduzir a uma espécie de pseudo-equilíbrio, estável durante algum tempo, mas produzir depois uma descompensação de toda a capacidade relacional. Ou, então, uma neurose, ou psicose latente ou «encapsulada», num ou noutro dos partenaires que, com a passagem do tempo, se pode tornar activa e perturbar profundamente a vida do casal em questão.

A nascença de um filho ou, pelo contrário, a descoberta de uma esterilidade podem desempenhar este papel de elemento desencadeador de uma neurose ou psicose latente. Ou, para terminar, a constatação, pelo casal, de não corresponder a certos padrões culturais, por exemplo aqueles preconizados para um casal considerado ideal, pode produzir o mesmo resultado. Fenómeno idêntico se verifica no plano especifico do funcionamento sexual.

Estas manifestações psicopatológicas poderiam provavelmente aparecer com outros companheiros diferentes daquele que foi escolhido, como poderão reproduzir-se, mais tarde, com outros companheiros eventuais.

No caso das «doenças do casal» não parece existir, pelo contrário, uma psicopatologia pré-existente nos elementos constituintes do casal. Aquelas resultam, aparentemente, mais da dinâmica de um dado casal, pela convergência de factores internos próprios do casal, ou por acção de factores externos, inclusive culturais. Pode-se supor que em outras circunstâncias ou com outros companheiros, tais perturbações poderiam não se ter gerado.

Alterações importantes na atitude de um dos cônjuges, o impacto de doenças físicas, problemas socioeconómicos, a aparição de um terceiro personagem na relação, frustraçōes narcísicas marcadas, etc., tudo isto sãó elementos capazes de provocar «ex-novo» uma doença no casal. Poder-se-ia discutir a acção de eventuais factores predisponentes, assim como se poderia recorrer a noções como as de uma inevitável «guerra dos sexos», mas do ponto de vista clínico, a distinção destas alterações daquelas que estão ligadas a uma psicopatologia já existente, parece-nos fundamental.

As «doenças do casal» ainda não foram submetidas a uma clarificação nosográfica satisfatória. É, no entanto, possível agrupá-las, grosso modo, em três ordens de manifes. tações perturbadoras.

Em primeiro lugar dificuldades de comunicação. Os dois associados do casal vão sentir-se envolvidos por inibições afectivas e emocionais, por um descontentamento crescente, por desejos de separação, etc., mas, no conjunto, o que está verdadeiramente perturbado é a capacidade de comunicação, tanto a nível verbal como infraverbal. As palavras nesses casos podem ser utilizadas para evitar o diálogo, ou mesmo para evitar toda a relação. Ou ainda os níveis de comunicação situam-se em perspectivas diferentes, de modo que os cônjuges julgam falar um com o outro, sem na realidade o fazerem.

Em segundo lugar as dificuldades afectando a vida sexual, sob a forma de disfunções variáveis, momentâneas ou persistentes, de falta de alento, ou de insatisfação em geral.

As deficiências de comunicação podem naturalmente tomar a forma de disfunções sexuais, mas é fácil de despistar a sua verdadeira natureza. Como dificuldades sexuais, propriamente ditas, consideramos aquelas que parecem atingir predominantemente os niveis do descjo ou do prazer e isto mesmo em presença de um grau de comunicação suficiente.

Finalmente há díficuldades na gestão da agressividade. Aqui os cônjuges alcançam o ponto de não querer reconhecer a existência possivel de qualquer agressividade, que está então escondida, cuidadosamente evitada ou negada. Pode isto ir até uma complacência de tipo agressivo, onde a ligação se limita a ser uma coligação contra qualquer coisa e onde a desavença se torna a linguagem de base. Assim se pode chegar também a manifestações de violência aberta.

Enquanto as respostas terapêuticas em face das «doenças no casal» podem ser muito variáveis de acordo com as perturbações origi- 
nárias, as respostas terapêuticas perante as «doenças do casal» são, de momento, mais empíricas. Podem orientar-se num sentido psicanalítico, visando a consciencialização nos dois cônjuges de desencontros subjacentes ao seu comportamento, que os conduzem a atitudes inadequadas.

As intervenções terapêuticas também se podem focalizar, ao contrário, numa forma ou outra de reeducação da comunicação, que pode socorner-se de várias técnicas indo da análise transaccional, até aos princípios sistémicos do desempenho de papéis, até ao método de Masters e Johnson, etc.

As intervenções podem visar a recolha de modo meticuloso de todo o material de fantasia, não espontaneamente verbalizado, ou camuflado por esteriótipos, para convidar o casal em questão a utilizar este material numa nova perspectiva. Por outras palavras, investigar a perturbação, em vez de a combater, para renovar o casal, para que ele assuma o «risco» de se considerar a si mesmo de modo diferente.

\section{RESUMF́}

L'auteur confronte au début les hypotèses du couple naturel biologique et du couple de base culturelle. Cette bipolarité constituante ne sera que difficillement depassée.

Du point de vue psychologique le couple représente une défense tant anaclitique que narcissique. Â notre époque trois événements revolutionaires dans la famille ont atteint le couple: 1) le fin de la famille patriarcale remplacée par la famille nucléaire plus instable; 2) l'égalité des deux sexes; 3) la contraception éficace créant une paternité et maternité responsables.

L'essai de définir un couple normal sera probablement abérrant. Plus importante est la discussion de la psychopatologie du couple. On peut séparer les «maladies dans le cou- ple», résultat d'anomalies pré-existantes, des «maladies du couple» qui apparaissent «ex-nova». Dans ces dernières on propose la classification suivante: a) difficultés de communication; b) troubles d'ordre sexuel; c) troubles dans la gestion de l'agressivité.

Les interventions concernant les «maladies du couple» doivent être orientées vers les trois points signalés, de facon à essayer de renouveler le couple.

\section{SUMMARY}

The author confronts first the hypotheses of the biologic couple versus the hypotheses of the couple with a cultural basis. This bipolarity does not seem easy to by pass.

From a psychological point of view the couple represents a defense mechanism both of an anaclitic ond narcissistic nature. In our times three revolutionary events have modified the structure of couples: 1) the end of the patriarchal family replaced by the nuclear family, of a less stable nature; 2) the equality of the sexes; 3) an efficient contraception rendering motherhood and fatherhood more responsible.

The attempt of defining a normal couple is probably an error. More important is discussing the couple's psychopathology. A separation should be established between the "diseases in the couple», resulting from pre-existing anomalies, and the «diseases of the couple» appearing «ex-novo». In the last group the following varieties can be pointed out: a) disturbances in communication; b) sexual malfunctions; c) disturbances in the administration of agressiveness.

The therapeutic interventions concerning the «diseases of the couple» should be oriented towards the three areas described, and should have in mind the renewal of the couple. 